\title{
THE OLD ORDER CHANGETH
}

\begin{abstract}
A s I peer into the darkness ahead, I seem to perceive a slight glimmer of light at the tunnel's distant opening - and in this instance the faint glow does not appear to be what it usually is, an indication that a locomotive and its string of heavily laden freight cars are bearing down on me. If some have detected a greater spring in my step of late they may have attributed it to that tunnel-end illumination, which represents the end of my term as editor of Latin American Antiquity. There are, however, other very good reasons, all $L A A$-connected, for my feeling that much, if not all, is going right with the world. I begin with the most important news, for you as well as for me:
\end{abstract}

\section{With Failing Hands I Pass the Pen to Thee}

Just when it appeared that I might be made Editor-for-Life (as the size of my stock of personalized SAA stationery suggested I might), a champion emerged to take up the editorial weapons and do batthe against the endless onslaughts of dangling participles and split infinitives. At next April's annual meeting I shall lay the great golden $L A A$ mantle upon the shoulders of Wisconsin's Gary Feinman, whose experience in the editing field is more than sufficient to give him a sense of how patty-strewn the pasture into which he is stepping can sometimes be. Gary is already at work on manuscripts for the first issue that will appear with his name on the masthead, and in addition he has taken an important step to change the nature of the editor's position. He is now officially co-editor-designate with Linda Manzanilla of Universidad Nacional Autónoma de México, who brings to the editing work not only extensive experience in the archaeology of Mexico but also a background of several years' editing of $L A A$ 's Spanish abstracts, a task she added to her normal duties as an Editorial Advisory Committee member. This new arrangement makes Latin American Antiquity more fully the archaeological journal for the Americas than it has been until now, and Gary deserves our heartiest congratulations for an innovation that I wish I had had the foresight to initiate.

I am sure that I shall continue to receive manuscripts until my term comes to an end, and even beyond that momentous day, but given the various time-lag factors that beset the $L A A$ editing process (more on this in a moment), authors should begin sending their work directly to Gary now.

\section{If You're Trying to Cut through the Tangles, Is the Pen Mightier than the Sword?}

It cannot have escaped the notice of $L A A$ 's readers that the month in which an issue arrives is not the month named on the cover, which is invariably one that played out its span quite a while earlier. Questions about this discrepancy arise frequently and from many quarters, and in response I have commented in past editorials on some of the stumbling-blocks we confront in the production process. Let's face it; in any but the most cutting-edge electrocybertronic world (where we clearly have not resided up to now), the arrangements that have made the appearance of the SAA's two journals possible thus far sound absolutely ludicrous. With one editor in Honolulu, the other in Toronto, the managing editor in Washington, D.C., and the press in Lawrence, Kansas, it is a wonder that the journals have got out at all-especially when the process has involved transmission of pencil-edited copy and diskettes by mail to the society's central office for Janet Walker's encoding and other ministrations so that the press could produce what the editors had made of the authors' original scrivenings. This remarkable situation, in which we had one foot in the computer age and the other somewhere back around the sleevegarter-and-green-eyeshade era, has unquestionably contributed to $L A A$ 's calendric problems. Take 
heart, however, for with this issue the society has made the critical quantum leap into the ethereal realm of desktop publishing, a step that may eventually help to eliminate many of the time-thieving facets of the past operation. Somewhere in the combination of this change with Gary's advance editing of issues for the next volume and the emergence of the dual editorship lie all the keys, I am convinced, to improve the punctuality of the journal in order to match the quality of its contents.

\section{Pen a Missive to Your Local Librarian}

I have written a good deal about means of extending the subscription list for $L A A$, and I hope that by now some of you have adopted a Latin American individual or institution as the recipient of a subscription for which you have undertaken to pay. Beyond the audiences reached by this and other efforts, however, lies a vast and largely untapped field of potential subscribers: North American institutional libraries. I know that we are not in the best of economic times, and that many librarians are actively seeking to reduce their journal lists. I also know, though, that the cost of $L A A$ is minuscule alongside those of journals in the sciences; when my institution's library puts out a request for list cuts, my department's attempts to pare back a bit are always met with the gentle message that those sorts of amounts don't really count on the budgetary battlefield. If they do not count as cuts, then they should not count as additions. Take up your pens (well, all right, PCs; I am just stuck on a pen theme as a result of the first section of this editorial) and write your institution's librarian today; sometimes it can be absolutely salutary to be told that you do not count.

\section{Out of the Penumbra and into the Light}

Before you receive this issue you will have seen the new membership arrangements, which allow a choice between American Antiquity and Latin American Antiquity. This shift should, I think, dispel the notion common in Latin America, which is that the SAA's original journal is the flagship, and $L A A$ nothing more than a dinghy wallowing in the great vessel's wake. I hope this will mean that we-or Gary and Linda, I mean - receive many more manuscripts from Latin American authors, and especially manuscripts in Spanish. The flow from Latin American sources continues to be encouraging, but too many of the papers are in English, presumably because the authors see that language as the better medium for full communication within our field. That perception is not, and cannot be allowed to appear to be, correct. If $L A A$ is truly to serve as a bridge among all of us whose focus is Latin America, and if it is not to convey the unacceptable message that Spanish is somehow a secondary language for the reporting of work done in a Spanish-speaking world, it must be a truly bilingual journal. I hope that as one concomitant of the journal's new status we shall see acceptance by all of our contributors and readers of the two languages as absolutely at par-and that we shall begin to see work by Brazilian authors in the pages of $L A A$ as well. 